\title{
LONGSHORE SEDIMENT INTERRUPTION AND BYPASSING OF A MULTIPURPOSE ARTIFICIAL REEF - PRELIMINARY RESULTS
}

\author{
GUILHERME VIEIRA DA SILVA ${ }^{1}$, DARRELL STRAUSS ${ }^{1}$, SAEED SHAERI $^{1}$, \\ THOMAS MURRAY ${ }^{1}$, RODGER TOMLINSON ${ }^{1}$, DANIEL HAMILTON ${ }^{2}$
}

1. Griffith Centre for Coastal Management, Griffith University, G512.07 Gold Coast Campus, QLD 4216, Australia. g.vieiradasilva@griffith.edu.au d.strauss@griffith.edu.au $\quad$ s.shaeri@griffith.edu.au $\quad \underline{\text { t.murray@griffith.edu.au }}$ t.tomlinson@griffith.edu.au

2. City of Gold Coast, PO Box 5042 Gold Coast Mail Centre, QLD, 9729, Australia. d.hamilton@goldcoast.qld.gov.au.

\begin{abstract}
Nearshore morphological changes and sand bypassing of multipurpose artificial reefs (MAPR) are still under reported in the literature. This research aims to further understand the bypassing of a MPAR to inform maintenance campaigns and construction of similar structures. Therefore, it was subdivided into three main parts: 1) long-term data analysis; 2) short-term data analysis and; 3) numerical modelling. This paper presents the preliminary results of this research focused on the first part. The results indicate that the reef has an overall positive impact on the upper beach with a minor negative downdrift effect. Most of the reef impact occurs in the nearshore and updrift sand trapping has been observed. Downdrift of the reef an accumulation of sand has also been observed in the nearshore. Preliminary assessment suggests that this is likely related to longshore bars intersecting or bypassing the reef. The next steps of this research are also presented.
\end{abstract}

\section{Introduction}

Interruptions in longshore sediment transport by natural (e.g. headlands, inlets) or artificial coastal structures (e.g. groynes, breakwaters, submerged structures) and their bypassing are often associated with cyclic erosion / accretion of downdrift areas. The erosion associated with this process is a major threat for coastal communities often leading to loss of private and public property as well as recreational amenity. Whilst the bypassing process was initially described in the 1940's by Evans (1943), during the last two decades the study of sediment bypassing has received much more attention in the scientific community. Recent research has demonstrated that for microtidal environments, the process is primarily driven by wave action, in particular wave direction (Vieira da Silva et al. 2018). McCarroll et al. (2018) studied the bypassing process in a macrotidal environment and demonstrated that tides may significantly affect embayment circulation and the bypassing process. Understanding the process and the transport rates related to different wave directions and driving mechanisms is of particular importance when preparing cities for changing wave climate (Hemer et al. 2013; Goodwin et al. 2016). 
Similarly to headlands, man-made structures such as groynes and breakwaters that act by (partially) interrupting longshore sediment transport and dissipating wave energy are often adopted as options to mitigate erosion. The use of multipurpose artificial reefs - MPAR - (either in combination with other measures or independently) to protect the coastline and improve surfing conditions began in the late 1990's. To date, however, only a few MPAR's have been built and the available post-construction information on the success of these as a coastal protection structures is mostly focused on the shoreline or upper (dry) beach profile. Therefore, the City of Gold Coast ('the City') and Griffith Centre for Coastal Management (GCCM) have developed a research plan aiming to further understand the morphological changes (both upper beach and nearshore) and associated sand bypassing around an existing artificial reef located at Narrowneck, Gold Coast, Australia. The outcomes of the research plan are designed to inform future maintenance programs of the artificial reef as well future MPAR projects. This paper will present the proposed steps and methods as well as preliminary results of the research.

\section{Study Area}

Narrowneck artificial reef is located on the Gold Coast, Queensland, Australia (figure 1). The Gold Coast's beaches are subject to moderate to high wave energy with significant seasonal and inter-annual variation. A wave buoy deployed at 70 $m$ depth offshore of the Gold Coast (Brisbane buoy) has recorded waves heights since 1976 and directional data since 1996 (Queensland Government). According to Vieira da Silva et al. (2018) the highest Hs recorded during the period was 7.2 $\mathrm{m}$ with an associated Tp of $12.2 \mathrm{~s}$ and the predominant wave direction is from SSE. As a result the net longshore transport is in the northerly direction, which plays a significant role in controlling sediment transport along the coastline. At the Gold Coast, summer is the most energetic period followed by autumn, winter and spring. According to Vieira da Silva et al. (2018), the wave attenuation along the Gold Coast is highly influenced by offshore wave direction. Tides are semidiurnal and micro-tidal, ranging from 0.2 to $2.1 \mathrm{~m}$ with mean range of $1 \mathrm{~m}$ (Kobashi et al., 2014). Sand is fine $(0.22 \mathrm{~mm})$ and mainly composed of quartz (Strauss and Tomlinson, 2009). Depth of closure calculated based on historical data is at $-14 \mathrm{~m}$ AHD (Australian Height Datum - which is approximately equivalent to local mean sea level, Strauss et al., 2013).

The Gold Coast has a history of cyclic shoreline erosion and accretion, with several large erosion events occurring since the 1900's. During the 1960's a sequence of extreme storms caused major erosion along the open coast beaches and a series of management measures were put in place to protect the coast, including the construction of a seawall along the coast (known as A-Line) that is buried under the dunes as protection against extreme events. As part of the 
Northern Gold Coast Beaches Protection Strategy, established by the City, the world's first MPAR was idealised and constructed in 1999 to protect a narrow land area (100 m wide) between the sea and the Nerang River. Construction of the artificial reef concluded in December 2000, with the reef consisting of 408 sand filled geotextile containers (Jackson et al., 2012). Since December 2000 an additional 126 bags have been placed on the reef as part of four "top-up" maintenance campaigns, the latest of which concluded in June 2018. The Narrowneck artificial reef remains the largest MPAR installed in the world to date, with the V-shaped reef approximately an order of magnitude larger than the next MPAR's. A full description of reef size, shape, material and construction methods is presented in Jackson et al. (2007; 2012).

The MPAR's role is to act as a control structure and stabilize the nourished beaches immediately to the south with planned average annual trapping of sediment of up to $100,000 \mathrm{~m}^{3} / \mathrm{yr}(20 \%$ of the total annual estimated longshore sediment transport on the Gold Coast) with a secondary goal to improve surfing conditions. The morphology around the reef has been monitored by the City since its construction in 1999 with a primary focus on cross-shore profile lines (called ETA lines) spaced $400 \mathrm{~m}$ apart (from the dune to below the depth of closure). Strauss et al. (2017) analysed this data and suggested that the majority of the morphological changes in and around the vicinity of the Narrowneck MPAR have occurred in the nearshore region. According to the authors, the reef (and associated offshore bars) have been shown to successfully dissipate wave energy and protect the coast. The City undertook a large scale nearshore nourishment (updrift) and reef top-up was completed in early 2018. Following these works, a higher temporal/spatial resolution monitoring program has been established by the City and GCCM to obtain a more complete understanding of the MPAR impacts on the coastal morphology with particular focus on the sand bypassing.

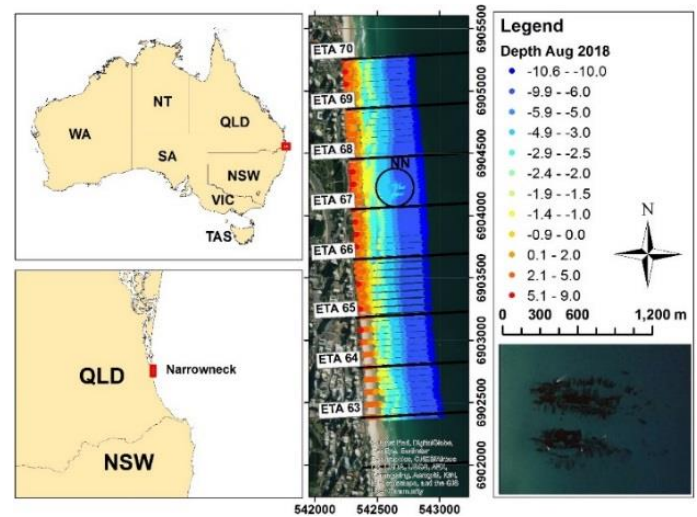

Fig. 1. Study area, detailed bathymetry, historical profile lines (ETA lines) and aerial image of the Narrowneck reef. 


\section{Methods}

To achieve the goals of this research the methodology was divided into three main steps: 1) Historical data analysis; 2) New data collection and analysis, and; 3) Numerical modelling. The first step, historical data analysis, has been completed and the results are presented in this paper.

\section{Historical data analysis (long-term)}

Due to cyclic erosion patterns and a willingness to innovate coastal management measures, the Gold Coast became one of the most studied coastal cities in the world. A rare dataset of beach profiles from the upper beach to the depth of closure started to be collected in the 1960's. In the past, surveys were more resource intensive and were undertaken less frequently, leaving gaps in the data sets. However, with technological improvements and reduction of survey costs it has become more frequent over time.

Historical data analysis was based on beach surveys of the main ETA lines between ETA 63 and ETA 70 (see figure 1). This part of the research was subdivided into two main analyses: 1) trend analysis with the aim of identifying (changes in) trends pre- and post- construction of Narrowneck reef and; 2) identifying where the greatest positive and negative impacts of the reef are on the beach and nearshore region. For the first part, the distance and volume of the beach profiles were calculated using the top of the seawall (A-Line) as a baseline reference to the shoreline distance ( $0 \mathrm{~m}$ AHD) and the depth of closure $(-14 \mathrm{~m}$ AHD). For the second part, average profiles before and after construction were also calculated to the shoreline and to the depth of closure. The results were compared between ETA lines to gain a broader understanding of the impact of the reef on the beach and nearshore region and to generate a baseline for the bypassing analysis.

\section{Shoreline and depth of closure trends}

This part of the research looked into trends in shoreline position and depth of closure distance and volumes. Initially the dataset was divided into two parts: 1) pre-construction and 2) post-construction. However, a clear change in trends was observed at around 2013 (13 years post construction). This observable change in shoreline and volume under the profile has been attributed to: a) a large scale upper beach nourishment campaign at Narrowneck in 1999-2000 (prior to reef construction) and b) major storms occurring in 2009 (primarily an East Coast Low - ECL - in May) and in 2013 (Tropical Cyclone Oswald - TC Oswald - in January). Both extreme weather events caused severe erosion on the Gold Coast and aided the trend of reduced beach width and volume (particularly at the 
shoreline). Therefore, for the present analysis, the data was divided into 3 periods: 1) pre- Narrowneck reef construction (1965-1999); 2) Post-construction to TC Oswald (2001 - 2013) and; 3) post TC Oswald (2013 onwards).

\section{Average profiles pre and post Narrowneck reef construction}

This analysis aimed to understand the impacts (positive and negative) of the reef on morphological changes in the nearshore region around the reef. While it is difficult to quantify the effect of beach nourishments on morphological changes, by analysing adjacent profiles it is possible to understand the relative impact of the reef along the beach. Turner (2006) suggested that the reef would have a groyne effect, therefore, it is expected that a larger volume (and wider beach) are present updrift of the reef compared to the downdrift area where a reduced volume and narrower beach would be expected. Furthermore, the larger underwater impact of the reef described by Strauss et al. (2017) should also be observed.

As trends in the profile data were analysed for the shoreline and depth of closure contours, the secondary analysis focused upon comparing the average profiles pre-construction and average profiles post-construction for the study area. For this analysis the pre-construction beach profiles are considered to be all profiles up to 1999 while the post-construction are all profiles measured from 2001. An analysis of the impact of the 2018 reef top-up and 2017 beach nourishment on individual profiles within such a short time period after the events is not possible without a very high survey frequency. As such this analysis is beyond the scope of the study presented here.

\section{New data collection (short-term)}

New data collection is currently being undertaken by the City and GCCM. It consists of measuring bathymetry and topography, waves, currents and sediment transport in the vicinity of the reef. The data collection is aimed at understanding the hydrodynamic and short-term morphological responses to the presence of Narrowneck reef. This dataset will also allow a morphological model calibration to obtain further details of morphological changes under conditions not captured by the current survey program.

\section{Topo-bathymetric surveys}

Topo-bathymetric surveys commenced in July 2018 and are aimed to be conducted approximately every 8 weeks. Survey covers $2800 \mathrm{~m}$ (alongshore) from ETA 63 to ETA 70 and extends from the dune to the $-10 \mathrm{~m}$ contour (see samples in figure 1). Close to the reef (covering $700 \mathrm{~m}$ ) the spatial resolution 
between survey lines is $25 \mathrm{~m}$, followed by a $50 \mathrm{~m}$ spacing to the north $(700 \mathrm{~m})$ and south (1400 m) (figure 1).

The data captured will be used to understand the short-term impact of the reef on the coastline and nearshore morphology and the bypassing process around the reef and relate these changes to the environmental conditions between surveys. Morphological changes and volumes will be quantified aiming to identify sediment pathways / transport rates and conditions that generate both parts of the bypassing process: capture (updrift) and release (downdrift) of sediment. It is expected that a minimum of one year dataset will capture a range of environmental conditions and provide meaningful information on the bypassing process. The analysis, however, will be limited to the conditions occurring between surveys and a numerical model will be calibrated and used to simulate conditions that were not measured.

\section{Nearshore instrumentation}

Nearshore measurements of waves, currents and sediment transport will be carried out to gather information on the actual performance of the MPAR in terms of wave transmission, changing hydrodynamic conditions, sediment transport around the structure, as well as to support future numerical modelling exercises. This part of the project is currently in planning phase and will be carried out in 2019.

\section{Numerical modelling}

Despite the unique dataset captured by the City to date and the considerable effort to capture higher spatial and temporal resolution data during this project, it is likely that some conditions will not be covered during the timeframe of this research. By using the offshore wave data, measured winds and water levels and the nearshore measurements, a process-based numerical model will be calibrated (waves, currents, water levels, sediment transport and morphological changes) so that it will be possible to analyse the impact of conditions not surveyed during the course of this research. Finally a conceptual model will relate the environmental conditions to the morphological changes and reef sand bypassing. This part of the research is in its initial phase.

\section{Results and Discussion}

The results presented here encompass the first part of this research: Historical data analysis. These are preliminary results of the project intended to provide background information on the impact of Narrowneck reef on the nearshore 
region, generate background information on bypassing and analyse the reef's role as control structure. The results will directly inform the local government in order for them to better understand, mitigate and manage their coastal assets.

\section{Historical data analysis}

Over 500 individual beach profiles have been surveyed between ETA 63 and ETA 70 since the early 1960's. An example of the surveys conducted at ETA 67 (just updrift of the reef) is presented in figure 2. The A-line seawall was built following storms in the 1960s to protect the coastal assets and, therefore is co-located with the scarp generated by that sequence of storm events. The seawall is currently buried under the dunes and acts to limit the extent of coastal erosion.

Two offshore storm bars are observed (figure 2) from the most significant storm periods: the sequence of 1960's storms and the 2009 storm, both with an outer bar crest below $-5 \mathrm{~m}$ (AHD). Highest standard deviation at the start of the profile is related to the large erosion in the 1960's and the present stable dune system protecting the coast. Between 200 and $400 \mathrm{~m}$ seaward and between 400 and 600 $\mathrm{m}$ is where two other minor standard deviation peaks are present - both linked to the offshore bars that are highly variable (figure 2).

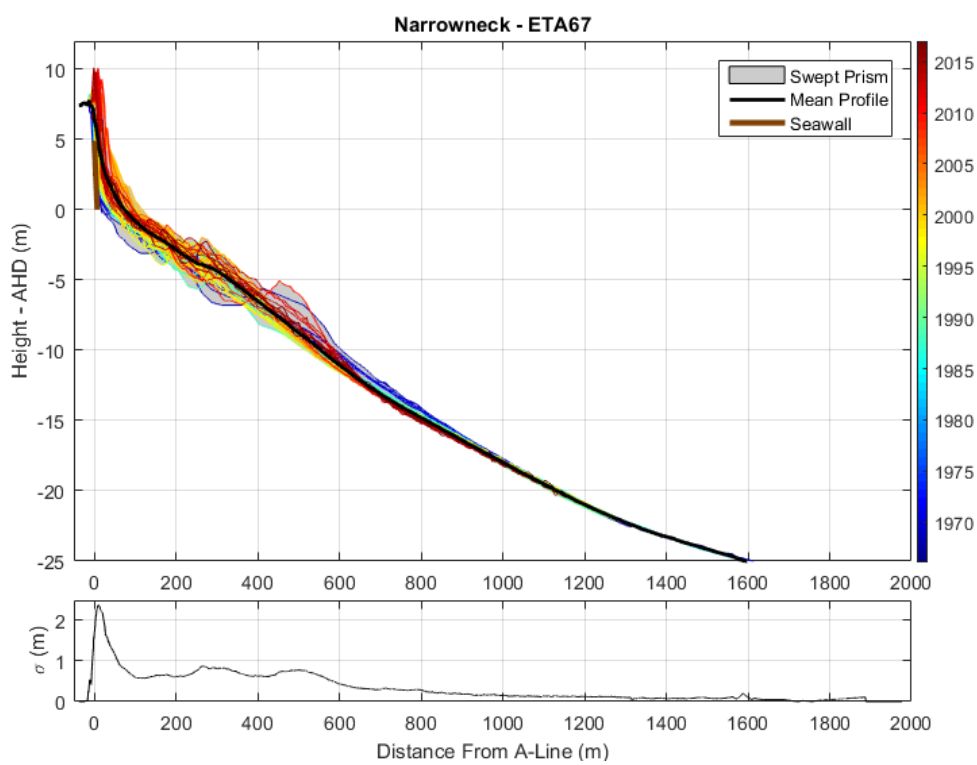

Fig. 2. Example of measured profile around Narrowneck (top). Colors represent the survey dates Standard deviation (bottom) of the profile elevation indicating the most active parts of the profile. 


\section{Shoreline and depth of closure trends}

Figure 3 presents the trends in distance and volume to shoreline (0m AHD) between ETA 63 to ETA70, under each profile. It is clear that after the 1960's storms and early beach nourishments in 1974-75 and 1985 the upper beach tended to progressively recover with an average rate of $1.25 \mathrm{~m} /$ year $\left(4 \mathrm{~m}^{3} / \mathrm{m} /\right.$ year $)$ and expected fluctuations are observed due to erosive and accretionary periods. Following the construction of the artificial reef at Narrowneck, the upper beach nourishment, and the two main erosive events of 2009 and 2013, the beach tended to reduce in width $(-2.7 \mathrm{~m} /$ year $)$ and volume $\left(-9.6 \mathrm{~m}^{3} / \mathrm{m} /\right.$ year $)$. The highest erosion rates were observed at ETA $68\left(-10.7 \mathrm{~m}^{3} / \mathrm{m} /\right.$ year $)$ and ETA $69\left(-17 \mathrm{~m}^{3} / \mathrm{m} /\right.$ year $)$, possibly as a result of the reef's downdrift effect. This period was described by Helman and Tomlinson (2018) as a high erosion severity as a response to a shift in the Interdecadal Pacific Oscillation Index (IPO). After Tropical Cyclone Oswald (TC Oswald) the shoreline volume recovered at $3 \mathrm{~m} /$ year on average (15.6 $\mathrm{m}^{3} / \mathrm{m} /$ year). The only profile indicating reduction of beach width (although it increased in volume) was ETA 66. This is mainly a result of a normal beach fluctuation and the narrower upper beach towards the end of the analysed period. The upper beach volume, despite decreased beach width, presented an increasing trend (figure 3).
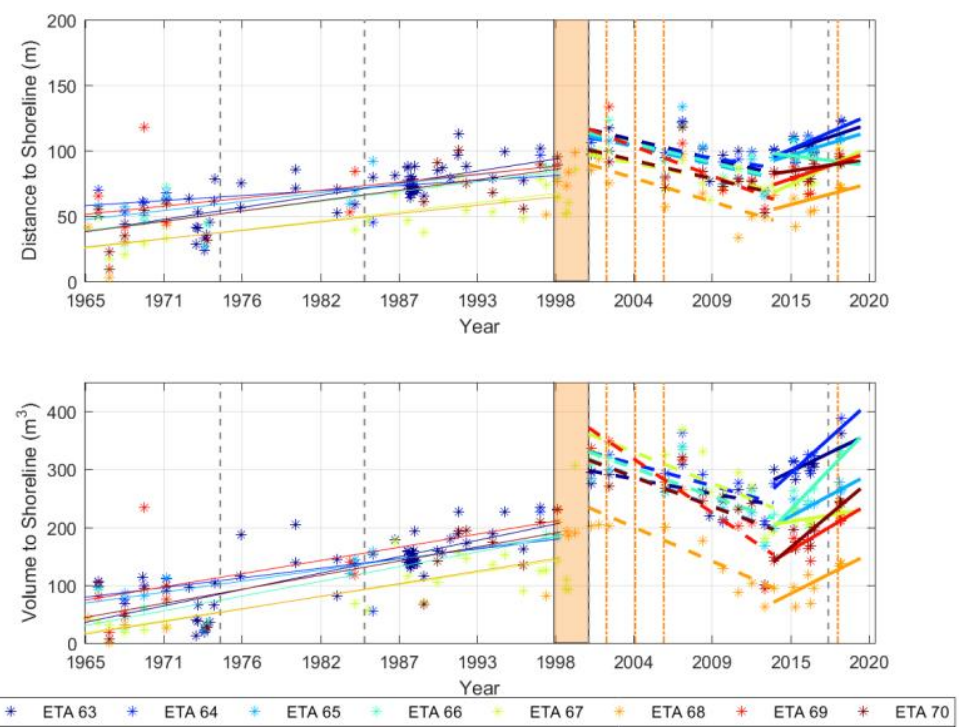

Fig. 3. Beach width (top), Beach volume (bottom). Black vertical lines: beach nourishments; Orange vertical lines: Reef top-ups; Orange rectangle: Reef construction.

As demonstrated previously by Strauss et al. (2017), shoreline position and upper beach volume are not necessarily a good measure of the beach health. Therefore, 
total volume was analysed down to depth of closure. Figure 4 presents the variations and trends of depth of closure distance from the A-Line (top of the seawall) and volume. The depth of closure contour is moving shoreward with trends of averaging $-0.9 \mathrm{~m} /$ year $\left(-1.2 \mathrm{~m}^{3} / \mathrm{m} /\right.$ year $),-6.15 \mathrm{~m} /$ year $\left(-1.5 \mathrm{~m}^{3} / \mathrm{m} /\right.$ year $)$, for pre-construction and post-construction to TC Oswald and seaward at 8.5 $\mathrm{m} /$ year $\left(4.61 \mathrm{~m}^{3} / \mathrm{m} /\right.$ year), Post TC Oswald. It is also clearly observed that the total volume of the profiles are above the pre-construction volumes, indicating that the reef is working by helping to stabilise the nearshore region.
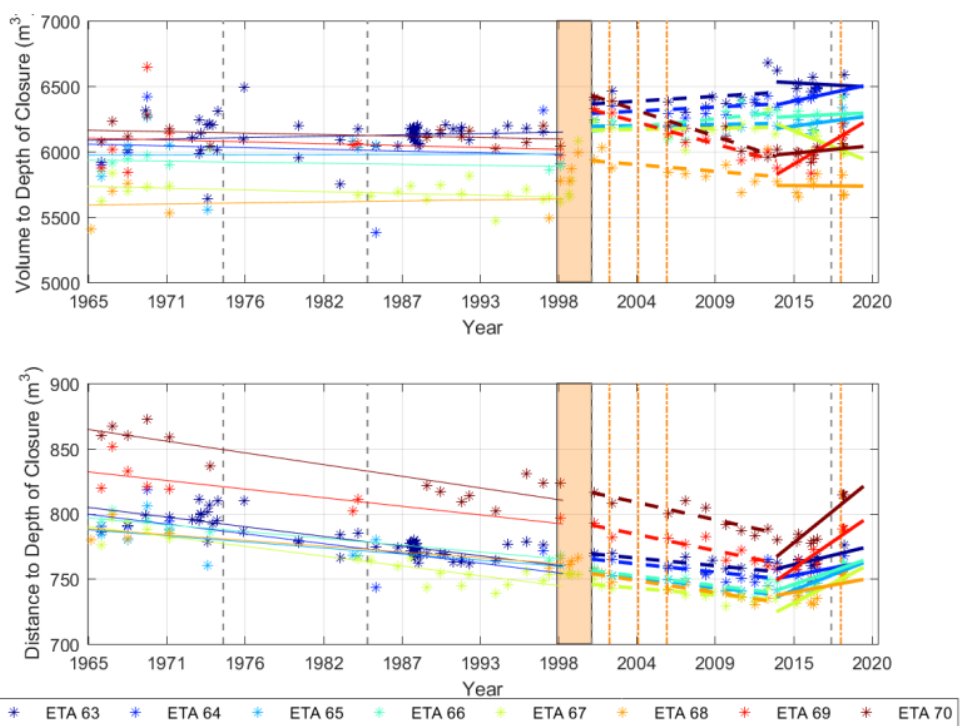

Fig. 4. Profile width (top); profile volume (bottom). Black vertical lines: beach nourishments Orange vertical lines: Reef top-ups; Orange rectangle: Reef construction.

\section{Average Profiles pre and post Narrowneck Reef Construction}

The average profiles before and after Narrowneck reef construction are presented in figures 5 and 6, respectively. Average profiles pre-construction updrift of the reef (figure 5 - black lines) indicate a generally more eroded profile, particularly on the upper beach. Below $-5 \mathrm{~m}$ at ETA 63 the average pre-construction profile presents a very similar shape to the post-construction average. As we move from ETA 63 towards Narrowneck reef (ETA 63 towards 67), the post-construction average profile below $-5 \mathrm{~m}$ tends to be seaward of what it was pre-construction. This finding corroborates with Patterson and Nielsen (2016) that suggest that sediment from the former Nerang river delta is moving onshore, acting as a supply of sand to the coast. Moreover, the pivot point (between pre- and postconstruction) gets deeper towards the reef and a greater sand accumulation is 
observed between -4 and $-7 \mathrm{~m}$ AHD towards ETA 66 indicating a greater accumulation of sand in the nearshore region for profiles updrift of the reef, as suggested by Strauss et al. (2017). ETA 67 (just south of Narrowneck reef) presents the pivotal point at around $-12 \mathrm{~m}$ (AHD) and a more evenly distributed accumulation of sand. This is likely a result of Narrowneck reef acting as a hold point for the longshore sediment transport to the north.

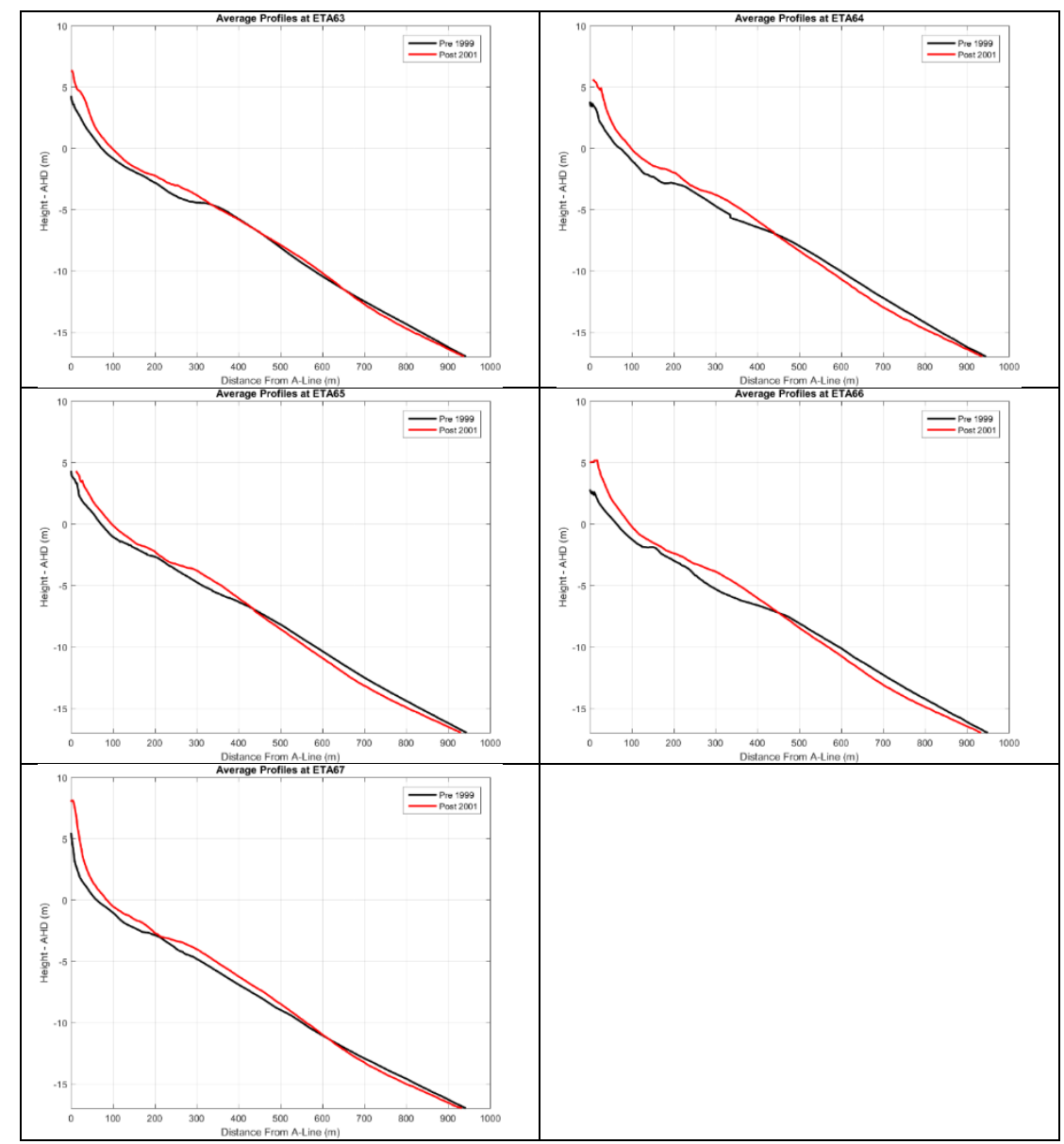

Fig. 5. Average profiles updrift of Narrowneck Reef. Black lines: pre-construction; Red lines: postconstruction.

Average profiles to the north of the reef (figure 6) demonstrate the expected downdrift groyne effect as suggested by Turner et al. (2006). The figure clearly indicates that the post-construction average upper beach profile is very similar to 
the average pre-construction, particularly for ETA 68 and 69 whereas updrift and at ETA 70 a wider upper beach is presented post-construction. This indicates that the negative downdrift impact of Narrowneck is limited to ETA 68 and 69 (approximately $700 \mathrm{~m}$ to the north of the reef). Additionally, more sand is present in this area at around -4 to $-7 \mathrm{~m}$, particularly at ETA 68, reducing towards ETA 69 and ETA 70. This accumulation of sand downdrift of Narrowneck is likely related to a bar attached to the reef. When present, a bar attached to the reef also has positive secondary impacts (surfing conditions) allowing for longer rides depending on swell direction.

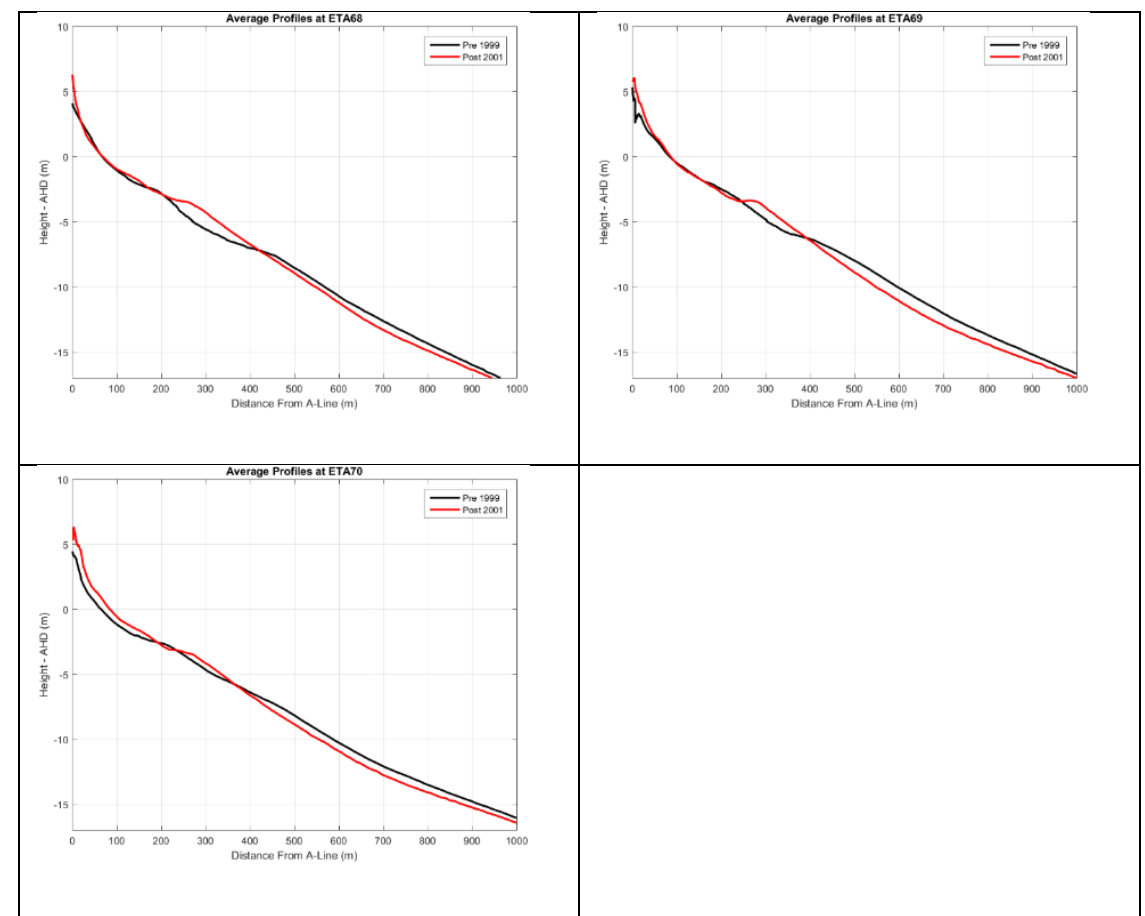

Fig. 5. Average profiles downdrift of Narrowneck Reef. Black lines: pre-construction; Red lines: post-construction.

\section{Conclusion}

To date only a few multipurpose artificial reefs have been constructed and there is still much knowledge to be gained on how these structures affect the coastline and nearshore areas within their vicinity. Long-term monitoring of existing structures and implementing high frequency spatial and temporal monitoring programs helps to improve the overall understanding of these structures in both long and short term. This paper presents the preliminary results of a research 
program looking into morphological changes and bypassing process around Narrowneck multipurpose artificial reef and correlating these to the environmental conditions. To date, the first of the three-step process has been completed and presented in this paper. This step analysed the historical dataset and looked at trends in shoreline and total profile volumes and width. The results presented here form the background information for the sand bypassing study and the influence that the Narrowneck reef has upon the beach and nearshore region.

The results presented here indicate that the upper beach profiles are wider and hold higher volumes post Narrowneck reef construction, with the area between 2 and $-6 \mathrm{~m}$ (AHD) being the most dynamic due to the presence/movement of bars. Three main trends were clearly observed:

1) Pre-Narrowneck construction (1965-1999): Following 1960's storms the upper beach around Narrowneck presented an overall recovery;

2) After construction and pre TC Oswald (2001-2013): the upper beach reduced its volume and width as a result of a reduction of the out of equilibrium profile (upper beach nourishment) and at least two major storms (ECL in 2009 and TC Oswald in 2013;

3) After TC Oswald (2013-onwards): Since TC Oswald the upper beach is increasing its volume and width.

The pivot point (between the average pre- and post-construction) gets deeper from ETA63 to ETA67 indicating that the reef is acting as a hold point, particularly for the nearshore region. A groyne effect is observed downdrift of the reef, particularly at ETA 68 and 69 where the upper profile shapes post construction are very similar to pre-construction. This effect is not observed at ETA 70, the nearshore region downdrift of the reef, however, a higher volume of sand is present and is likely related to the longshore bar attached to the reef.

Overall, the reef seems to be responsible for trapping sand on its updrift region with minor downdrift impact. The next steps of this research will look at the hydrodynamic and morphological changes in more detail and correlate these with the environmental conditions to produce a conceptual model of changes around the reef that could be used to inform both future reef maintenance campaigns and other reef construction. 


\section{Acknowledgements}

This research project was sponsored by the City of Gold Coast (the City) through a funding and collaboration agreement between the City and Griffith University. The City has provided data, including bathymetric survey, and project overview to assist in the understanding of this research topic and its benefit to the City.

\section{References}

Evans, O.F., (1943). "The relation of the action of waves and currents on headlands to the control of shore erosion by groynes". Academy of Science for 1943, pp. 9-13

Goodwin, I. D., T. R. Mortlock, and S. Browning, (2016). "Tropical and extratropical-origin storm wave types and their influence on the East Australian longshore sand transport system under a changing climate". Journal of Geophysical Research Oceans, 121, 4833-4853,

Helman, P., Tomlinson, R., (2018) "Two centuries of Climate Change and Climate Variability, East Coast Australia. Journal of Marine Science and Engineering 6(1).

Hemer, M.A., Fan, Y., Mori, N., Semedo, A., Wang, X.L., (2013). "Projected changes in wave climate from a multi-model ensemble". Nature Climate Change. V.3, 471-476

Jackson, A., Tomlinson, R., Corbett, B., Strauss, D. (2012). "Long-term performance of a submerged coastal control structure: A case study of the Narrowneck multi-functional artificial reef". Proceedings of the 33rd International Conference on Coastal Engineering, Santander Spain, 1-6 July 2012. 15 Pages.

Jackson.L.A., Corbetet.B.B., McGrath. J.E., Stuart.G. and Tomlinson.R.B. (2007). "Narrowneck Reef : Review of Seven Years of Monitoring", Shore and Beach, 75 (4), pp.67-79.

Kobashi, D., Strauss, D., Tomlinson, R., (2014). "Changing coastlines and processes". In: BURTON, P. (Ed.), Responding to Climate Change: Lessons from an Australian Hotspot. Gold Coast.

McCarroll, T.J., Masselink, G., Valiente, N.G., Scott, T., King, E.V., Conley, D., (2018). "Wave and tidal controls on embayment circulation and headland 
bypassing for an exposed, microtidal site". Journal of Marine Science and Engineering. 6, 94.

Patterson, D.C., Nielsen, P. (2016). "Depth, bed slope and wave climate dependence of long term average sand transport across the lower shoreface". Coastal Engineering, 117, 113-125.

Strauss, D., Burston, J., Tomlinson, R., (2013). "Multi-decadal analysis of profile response to permanent bypassin". In: Bonneton, P., Garlan, T. (Eds.), Coastal Dynamics. Arcachon, France, SHOM, 12pp

Strauss, D., Murray, T., Harry, M., Todd, D. (2017). “Coastal Data Collection and Profile Surveys on the Gold Coast: 50 Years on". Proceedings of Coasts \& Ports 2017 Conference. 7 pp.

Strauss, D., Tomlinson, R., (2009). "Modelling transitions between barred beach states on a straight coast". In: M, M., Sato, S. (Eds.), Proceedings of Coastal Dynamics 2009: Impacts of Human Activities on Dynamic Coastal Processes, pp. 1-11 (7 - 11 September, Tokyo, Japan).

Turner, I.A. (2006). "Discriminating Modes of Shoreline Response to OffshoreDetached Structures". Journal of Waterway, Port, Coastal and Ocean Engineering. 132(3), 180-191.

Vieira da Silva, G., Toldo Jr. E.E., Klein, A.H.F., Short, A.D. (2018). "The influence of wave-, wind- and tide-forced currents on headland sand bypassing - study case: Santa Catarina Island north shore, Brazil". Geomorphology, 312, 1-11. 